имеется достаточно специальной литературы по созданию кейсов (руководства). Для придания кейсам научной строгости, можно использовать статистические материалы. Из Интернета преподаватель может брать подтвержденные материалы, опирающиеся на известные источники [4].

После дискуссии преподаватель обязательно должен оценить деятельность каждого участника, повышая тем самым мотивацию к изучению предмета. Результатом применения метода в вузе являются не только знания, но и навыки профессиональной деятельности.

Подводя итог вышесказанному, можно сказать, что преимуществом метода кейсов является возможность оптимально сочетать теорию и практику в обучении. Наличие в структуре кейс-метода дискуссий и аргументации тренирует участников, развивает их коммуникативные навыки, то есть учит соблюдению норм и правил общения, учит четко выражать свои мысли.

Метод кейс-технологии обеспечивает освоение теории и овладение навыками практического использования материала; воздействует на профессионализацию обучающихся; формирует их интерес и позитивную мотивацию по отношению к учебе. Преподаватель становится фасилитатором, то есть помощником обучающихся в течение всего процесса обучения, решает и не допускает конфликты, создает обстановку сотрудничества. Не навязывая свое мнение, он добивается активного участия всех, присутствующих на занятии.

Таким образом, педагогический потенциал кейс-метода гораздо эффективнее, чем традиционные методы обучения, повышает качество образования. Практически, данный метод универсален, так как его можно использовать в преподавании любого предмета, что и происходит в настоящее время в нашем образовании.

$$
* * *
$$

1. Земскова А. С. Использование кейс-метода в образовательном процессе // Совет ректоров. - М.: 2008. - № 8. - С. 12-16.

2. Серебрянцева О.Г. Метод кейсов как развивающий элемент обучения в педагогическом учреждении - Наука России: Цели и задачи. Сборник научных трудов по материалам XXIII международной научно-практической конференции 10 октября 2020 г. Изд. НИЦ «Л-Журнал». 2020. -68 c.

3. Серебрянцева О.Г. Метод кейс-стади как средство развития коммуникативной компетентности в нелингвистическом вузе. - Международный научно-исследовательский журнал / Internatinal research journal. - Екатеринбург. - "А-принт", 2020 - № 2 (92), часть 2.

4. Федоринова 3.В. Использование case-study в организации образовательной деятельности (на примере преподавания английского языка) // Филол. науки. Вопр. теории и практики. - Тамбов: Изд-во «Грамота», 2010. - No. 1(5). - С. 210-215.

5. http://www.partnerstvo.nj/modules.php?name=Content\&pa=showpage \&pid=22

\title{
Сицинский Г.Ю. \\ Реализация национального проекта «Образование» в условиях пандемии: характеристики и проблемы
}

НОЧУ ВО «Московский финансово-промышленный университет «СИНЕРГИЯ» (Россия, Москва)

doi 10.18411/gq-31-03-2021-39

idsp sciencerussia-31-03-2021-39

\section{Аннотация}

В настоящей статье автор анализирует исполнение национального проекта «Образование» в сложных эпидемиологических условиях. Автор рассматривает финансовый аспект, структурные изменения национального проекта. Проводится анализ проблем, которые возникли во время пандемии, в первую очередь - проблему дистанционного обучения, внедрения современных цифровых технологий. В статье 
представлен вывод о двойственном характере реализации национального проекта «Образование» во время пандемии.

Ключевые слова: национальный проект, федеральный проект, дистанционное обучение, пандемия, образование, образовательная среда.

\section{Abstract}

In this article, author analyzes the implementation of the national project "Education" in difficult epidemiological conditions. Author examines the financial aspect, structural changes of the national project. The problems that arose during the pandemic are analyzed, first of all, the problems of distance learning, the introduction of modern digital technologies. The article concludes about the duality of the implementation of the national project "Education" in the context of a pandemic.

Keywords: national project, federal project, distance learning, pandemic, education, educational environment.

\section{Введение}

В начале 2020 года мир охватила пандемия новой коронавирусной инфекции COVID-19. Не обошла стороной вспышка данной эпидемии и Россию. Пандемия оказала серьезное негативное воздействие на экономику страны, начался экономический кризис. В изменившихся условиях реализация национальных проектов столкнулась с множеством вызовов.

Общим для всех нацпроектов был пересмотр финансовых показателей ввиду перераспределения денежных средств для поддержания экономики России, малого и среднего предпринимательства, сферы здравоохранения. На фоне кризиса выросли долговые обязательства и расходы предприятий. В то же время сами национальные проекты оказались недостаточно проработанными, что проявилось во время пандемии. Важным в данной ситуации является также и тот факт, что в начале 2020 года после послания Президента Федеральному Собранию и смены российского Правительства произошли некоторые изменения приоритетов в сфере социально-экономического развития страны. Тогда же ответственным за реализацию национального проекта «Образование» был назначен Министр просвещения Российской Федерации Сергей Сергеевич Кравцов, а куратором национального проекта стала заместитель Председателя Правительства Российской Федерации Татьяна Алексеевна Голикова.

Национальный проект «Образование» с введением режима самоизоляции начал испытывать трудности в реализации. В частности, оказалось, что развитие цифровых технологий, дистанционных и электронных образовательных продуктов находится на достаточно слабом уровне, не подходящем для чрезвычайных ситуаций [1]. Оснащение образовательной сферы средствами на базе современных информационнокоммуникационных технологий также оказалось недостаточным. Это же можно сказать и об уровне профессиональной подготовки педагогов, использующих средства ИКТ, особенно в сельской местности. Все вышеизложенные факторы в своей совокупности оказали сильное влияние на реализацию национального проекта «Образование».

\section{решения}

Российская система образования и пандемия COVID-19: проблемы и

Пандемия обнажила ряд проблем, существующих в отечественной образовательной системе. Сильную нагрузку получил федеральный бюджет из-за необходимости исправления ситуации в экономике. Образовательная среда оказалась под сильным внешним ударом, связанным с кризисом и самоизоляцией. В связи со вспыхнувшим кризисом неоднократно поднимался вопрос о сокращении расходов бюджета на национальные проекты. Однако впоследствии меры, принятые Правительством Российской Федерации, позволили сохранить финансирование нацпроектов в прежних рамках, поэтому общая финансовая сторона национального 
проекта «Образование» оказалось незатронутой. В то же время внутри национального проекта, на уровне федеральных проектов программ, было сделано определенное перераспределение бюджетных средств между различными направлениями, в основном - на поддержку цифровых технологий в области образования [8].

Одной из острейших проблем образовательной среды стал сильный дисбаланс, противоречие между материально-технической оснащенностью учебных заведений крупных городов и сельской местности, а также между отдельными учебными заведениями даже в рамках одного региона. Выяснилось, что ряд образовательных учреждений слабо готов или не готов вовсе к полному переходу на дистанционную форму обучения [4]. Обнаружились некоторые опасения со стороны педагогов полностью потерять живой контакт с учениками и студентами. Однако Правительство не намеревалось полностью заменить традиционную форму обучения дистанционной формой. Вместе с тем введение дистанционного обучения позволило дополнить традиционную форму, сделать ее более интерактивной, более современной, познакомить учащихся и педагогов с новыми технологиями.

Но еще более важной проблемой стала низкая культура владения ИКТ со стороны педагогов. Даже при использовании средств удаленного доступа к образовательным онлайн-платформам, ряд педагогов столкнулись со сложностями [3]. Такое положение дел, стоит отметить, возникло в образовательной среде довольно давно, однако наиболее ярко проявило себя именно в условиях начавшейся пандемии. Общую картину вновь вскрывшихся проблем во время пандемии в целом можно представить так:

1. Недостаточный уровень оснащения материально-технической базы образовательных учреждений;

2. Низкое качество Интернет-соединения;

3. Низкая информационно-коммуникационная и компьютерная грамотность отдельных педагогов (порядка 60\% всех педагогов до пандемии редко проводили или не проводили вовсе онлайн-занятия);

4. Отсутствие единой цифровой образовательной среды;

5. Дисбаланс в реализации нацпроекта между различными регионами, городской и сельской местностью, отдельными учебными заведениями, как среднего, так и высшего образования.

Вследствие вышеизложенных проблем был принят ряд решений, направленных на оптимизацию национального проекта «Образование». Так, уже летом 2020 года вузы стали проводить обучающие курсы и семинары, направленные на повышение информационно-коммуникационной и компьютерной грамотности педагогического состава. Учитывая, что сложные условия оказали негативное воздействие на психологическое состояние учащихся, возникла необходимость их адаптации к таким условиям. С этой целью в вузах были созданы службы, оказывающие психологическую поддержку как обучающимся, так и педагогам [9].

Не осталось без внимания и проведение Единого государственного экзамена. Правительством было принято решение, что сдавать ЕГЭ в 2020 году будут только те выпускники, которые намерены поступать в высшие учебные заведения. Сдача экзаменов проводилась с соблюдением всех санитарно-эпидемиологических норм, которые предписывал Роспотребнадзор. Большая часть результатов ЕГЭ оказалась соизмерима с уровнем таковых предыдущего, 2019 года. Государственная итоговая промежуточная аттестация проводилась в дистанционном режиме, что позволило улучшить и оптимизировать систему прокторинга - слежения за тестированием или экзаменом в онлайн-режиме.

В ноябре 2020 года в структуре национального проекта «Образование» произошел ряд изменений. Так, из нацпроекта были исключены такие федеральные проекты как «Новые возможности для каждого», «Экспорт образования» и отдельные 
положения и результаты проекта «Молодые профессионалы» [5]. Данные федеральные проекты были переданы из ведомства Министерства просвещения РФ в ведомство Министерства науки и высшего образования РФ, которое объявило о создании нового образовательного национального проекта, который получил название «Наука и университеты». Стоит добавить, что федеральные проекты «Учитель будущего» и «Поддержка семей, имеющих детей» были включены как составные части в федеральный проект «Современная школа» с целью оптимизации исполнения национального проекта «Образование» в целом. Дополнительно в структуру нацпроекта был включен новый федеральный проект «Патриотическое воспитание граждан РФ» [6].

Также, в конце 2020 года куратор национального проекта «Образование», заместитель Председателя Правительства РФ Т.А. Голикова сообщила, что в качестве эксперимента вводится единая цифровая образовательная среда. Она включает в себя комплекс мер, таких как инфраструктурные преобразования в средних учебных заведениях и блок содержания обновленного образовательного контента [7]. Данный контент включает в себя цифровые платформы, проектное обучение, виртуальные лаборатории, удаленное обучение иностранным языкам, доступ к электронным библиотекам и иным образовательным ресурсам и сервисам.

Одновременно с обозначенными мерами, специалисты Центра информационноаналитического и проектного сопровождения национальных проектов Академии Министерства просвещения РФ, который является ведомственным проектным офисом нацпроекта «Образование», подключили к единой образовательной системе региональные проектные офисы всех регионов РФ [2]. Такая система на текущий момент характеризуется, как эффективный инструмент мониторинга и осуществления контроля над реализацией нацпроекта «Образование» для ведомственного проектного офиса Министерства просвещения РФ.

Обозначенные нововведения, как структурного, так и содержательного характера имеют своей целью повышение качества и доступности образования в стране. Данные меры призваны обеспечить необходимый материально-технический и информационно-коммуникационный уровень с возможностью доступа к нему как педагогов, так и учащихся.

\section{Выводы}

В завершении статьи можно сделать вывод, о том, что общий характер реализации национального проекта «Образование» в условиях пандемии является двойственным, противоречивым. В целом система образования РФ прошла проверку на прочность, но одновременно с этим обнажился ряд проблем, стоящих перед ней. Двойственность же заключается и в том, что пандемия как негативное явление оказала положительное воздействие на развитие цифровых технологий в образовании в связи с массовым переходом образовательных учреждений на дистанционный режим.

Сложные условия оказались своеобразным срезом всех достигнутых на текущий момент результатов национального проекта. Пандемия показала сильные и слабые стороны в реализации национального проекта, обозначила имеющиеся проблемы. Несмотря на все положительные изменения и принятые в конце 2020 года меры, успешное исполнение национального проекта «Образование» во многом зависит от дальнейших грамотных, продуманных и четко сформулированных действий со стороны государства.

Для достижения изначальной глобальной цели нацпроекта «Образование» обеспечения конкурентоспособности российского образования и воспитание социально ответственной и гармонично развитой личности - необходимо дальнейшее повышение эффективности всей образовательной системы. Таковое невозможно обеспечить без внимательного контроля со стороны государства, большей согласованности в реализации нацпроекта, сотрудничества между отдельными регионами и ведомствами. 
Пандемия стала значительным стимулом для развития и использования ИКТ, дистанционного обучения и удаленного доступа к образовательным ресурсам. Не все учебные заведения и образовательные организации смогли быстро адаптироваться к подобным условиям, однако в целом удалось не допустить крайне негативных последствий в области образования. Пандемия хорошо показала важность использования современных технологий, позволила проанализировать недостатки, сделать определенные выводы, по которым в будущем можно будет повысить общую эффективность отечественного образования.

$$
* * *
$$

1. Кислов А.Г. Цифровой урок пандемии // Профессиональное образование и рынок труда. 2020. №2 (41). - C. $42-43$

2. Лутфуллаев Г.У., Лутфуллаев У.Л., Кобилова Ш.Ш., Неъматов У.С. Опыт дистанционного обучения в условиях пандемии COVID-19 // Проблемы педагогики. 2020. №4 (49). - C. 66-69

3. Мальцев В.А., Мальцев К.В. Пандемия и образование // Научные труды Вольного экономического общества России. 2020. №4. - С. 402-415

4. Муратова Л.В., Муратова А.С., Орлова К.С. Дистанционное обучение: первичный анализ данных оценки текущей ситуации // МНКО. 2021. №1 (86). - С. 285-289

5. Национальный проект «Образование». Министерство Просвещения Российской Федерации. [Электронный ресурс] Режим доступа: https://edu.gov.ru/national-project/

6. Национальный проект «Образование». Национальные проекты России. [Электронный ресурс] Режим доступа: https://национальныепроекты.pф/projects/obrazovanie

7. Сицинский Г.Ю. Национальный проект «Образование»: реализация, специфика и особенности // Социально-педагогические вопросы образования и воспитания : материалы Всерос. науч.-практ. конф. с междунар. участ. (Чебоксары, 18 февр. 2021 г.) / редкол.: Ж.В. Мурзина [и др.] Чебоксары: ИД «Среда», 2021. - С. 68-73

8. Тищенко А.С. Влияние пандемии на экономику образования // Экономическое развитие России. 2020. №5. - C. 90-97

9. Фомин А. А. Изменение стратегии образования в условиях пандемии // Digital. 2021. №1.

\section{Хачатурьянц В.Е., Теремов А.В.}

\section{Отражение изучения организма человека в мировом художественном искусстве}

ФГБОУ ВО «Московский педагогический государственный университет»

(Россия, Москва)

doi 10.18411/gq-31-03-2021-40

idsp sciencerussia-31-03-2021-40

\section{Аннотация}

Человек является самым сложным объектом изучения в биологии и отражением в изобразительном искусстве. Русская и мировая живопись богата выдающимися примерами изображения человека, как неиссякаемого источника творчества художника. Изучение человека со всеми его внешними и внутренними особенностями настолько важно и существенно, что учителю недостаточно на уроках использовать только материал учебников биологии и учебных пособий. Стоит вспомнить об анатомических рисунках и портретных картинах великих художников, которые подкрепят теоретический материал курса биологии и будут способствовать реализации интегрированного подхода с целью создания разносторонне развитой личности.

Ключевые слова: интеграция, межпредметный подход, изобразительное искусство и биология

\section{Abstract}

Man is the most complex and meaningful object of biology and fine arts. Russian and world painting is rich in outstanding examples of depicting a person as an inexhaustible source of the artist's creativity. The study of a person with all his external and internal characteristics is so important and essential that it is not enough for the teacher to use only the 